\title{
Phylogeny among the basidiomycetous yeasts inferred from small subunit ribosomal DNA sequence
}

\author{
Sung-Oui Suh and Junta SugiYama*
}

Institute of Molecular and Cellular Biosciences, The University of Tokyo, Yayoi 1-1-1, Bunkyo-ku, Tokyo 113, Japan

(Received 23 November 1992; revised 25 January 1993; accepted 25 February 1993)

\begin{abstract}
The sequence of the small subunit nuclear ribosomal DNA (18S rDNA) was determined for seven selected species of the teliospore-forming yeasts and Filobasidiaceae in the basidiomycetous yeasts. A phylogenetic tree, including published reference sequences, was inferred from 1623 sites which could be unambiguously aligned. The molecular phylogeny, using a chytridiomycete as an outgroup, divided the eight basidiomycetous yeasts into two groups which correlated well with both septal ultrastructure (simple pore or dolipore) and cellular xylose (present or absent). The first group included the teliospore-forming yeasts Rhodosporidium toruloides and Leucosporidium scottii, and Erythrobasidium hasegawianum, which is currently a member of the Filobasidiaceae. The second group was formed by the filobasidiaceous yeasts, comprising a Cystofilobasidium capitatum/Leucosporidium lari-marini/Mrakia frigida branch, and a Filobasidium floriforme/Filobasidiella neoformans branch. Our molecular data support the principal chemotaxonomic and ultrastructural evidence, which indicates a very close affinity between $C$. capitatum and $L$. lari-marini.
\end{abstract}

\section{Introduction}

Basidiomycetous yeasts have been classified into three taxonomic categories: the teliospore-forming yeasts, and the yeasts of the Filobasidiaceae, and the Tremellales (Kreger-van Rij, 1984a). Teliospore formation and basidial morphology were considered as primary taxonomic characters for the classification of the Filobasidiaceae and teliospore-forming yeasts. Rhodosporidium, Leucosporidium and Sporidiobolus were included in the teliospore-forming yeasts.

Since the publication of 'The Yeasts, a Taxonomic Study' (Kreger-van Rij, 1984b), several new basidiomycetous yeast genera have been proposed on the basis of chemotaxonomic and ultrastructural studies. Among these, the genera Cystofilobasidium (Oberwinkler et al., 1983), Mrakia (Yamada \& Komagata, 1987), and Kondoa (Yamada et al., 1989) have been separated from

*Author for correspondence. Tel. (03) 38122111 ext. 7827; fax (03) 3818 0444; email jsugi@tansei.cc.u-tokyo.ac.jp.

The nucleotide sequence data reported in this paper have been submitted to DDBJ and have been assigned the accession numbers D12801 (Cystofilobasidium capitatum), D12802 (Mrakia frigida), D12803 (Erythrobasidium hasegawianum), D12804 (Filobasidiella neoformans), D12805 (Leucosporidium lari-marini), D12806 (Rhodosporidium toruloides) and D13460 (Filobasidium floriforme). the genera Leucosporidium and Rhodosporidium in the teliospore-forming yeasts, and included within the Filobasidiaceae. Hamamoto et al. $(1988,1991)$ proposed the genus Erythrobasidium in the Filobasidiaceae for the teleomorph of Rhodotorula hasegawae. However, phylogenetic relationships among these basidiomycetous yeast taxa are still controversial. For example, recent chemotaxonomic and ultrastructural studies (Suh \& Sugiyama, 1993) have suggested that Leucosporidium lari-marini is related to the Filobasidiaceae.

The phylogenetic value of rRNA sequences has been discussed in recent reviews (Bruns et al., 1991; Kurtzman, 1992; Kohn, 1992; Hibbett, 1992). 18S rDNA (and rRNA) sequences have been especially useful in elucidating the evolution and phylogeny of fungi (Hendriks et al., 1991 a, b, 1992; Berbee \& Taylor, 1992 a, b; Van de Peer et al., 1992; Nishida \& Sugiyama, 1993). We report the 18S rDNA sequence and phylogenetic relationships of seven species of basidiomycetous yeasts. We compare our results with information on other taxonomic characters.

\section{Methods}

Cultures. The following yeast strains were used for sequencing: Rhodosporidium toruloides IAM $13469^{\mathrm{T}}(=\mathrm{IFO} 0559=\mathrm{CBS} 14$, mating type A); Leucosporidium lari-marini IAM $14213^{\mathrm{T}}$ (= CBS 7420, 
self-sporulating); Cystofilobasidium capitatum IAM $13521^{\mathrm{T}}$ (= ATCC 24507, self-sporulating); Mrakia frigida IAM $14136^{\mathrm{T}}$ (= CBS 5270, self-sporulating); Erythrobasidium hasegawianum IAM $12911^{\mathrm{T}}$ (= IFO $1058=$ ATCC 9536, self-sporulating); Filobasidium floriforme IAM $14212^{\mathrm{T}}$ (= CBS 6241, mating type A); Filobasidiella neoformans IAM $14211^{\mathrm{T}}$ (= CBS $6886=$ ATCC 28958 , mating type a). Strains with a superscript $\mathrm{T}$ are derived from the type. The yeasts were all grown in YM broth at $25^{\circ} \mathrm{C}$ for DNA extraction.

$P C R$ and sequencing. DNA was obtained from cells broken by sonication. The PCR and sequencing of 18S rDNA were done according to Nishida \& Sugiyama (1993).

Phylogenetic analysis. We sequenced the 18S rDNA of the seven basidiomycetous yeasts mentioned above and added known sequence data from the chytridiomycete Blastocladiella emersonii (Förster et al., 1990), the ascomycetous yeasts Candida albicans (Hendriks et al. 1989), Kluyveromyces lactis (Maleszka \& Clark-Walker, 1990), and Saccharomyces cerevisiae (Mankin et al., 1986), the filamentous ascomycete Neurospora crassa (Sogin et al., 1986), the basidiomycetous yeast Leucosporidium scottii (Hendriks et al., 1991b), the basidiomycetous anamorphic yeasts Sporobolomyces roseus, Bullera alba, and Trichosporon cutaneum (Van de Peer et al., 1992), and the ustilaginalean basidiomycete Ustilago maydis (De Wachter et al., 1992). Recently, the 18S rRNA sequences of $R$. toruloides and Filobasidiella neoformans were published by Van de Peer et al. (1992). Comparing their sequence data with our own, however, revealed three and eleven base differences in $R$. toruloides and Filobasidiella neoformans, respectively. All sequences were aligned using the multialignment program CLUSTAL $v$ (Higgins et al., 1992). Distances between the sequences were calculated using the two-parameter model of Kimura (1980). Sites where gaps existed in any of the sequences were excluded. A phylogenetic tree was constructed using the neighbour-joining method of Saitou \& Nei (1987). Bootstrap analysis (Felsenstein, 1985) used 1000 random samples from the multiple alignment. The tree was rooted using Blastocladiella emersonii as an outgroup.

\section{Results and Discussion}

For each strain, we sequenced about 1750 bases of PCR amplication product of the gene encoding 18S rRNA. The sequence data were well aligned for all 17 fungi, and

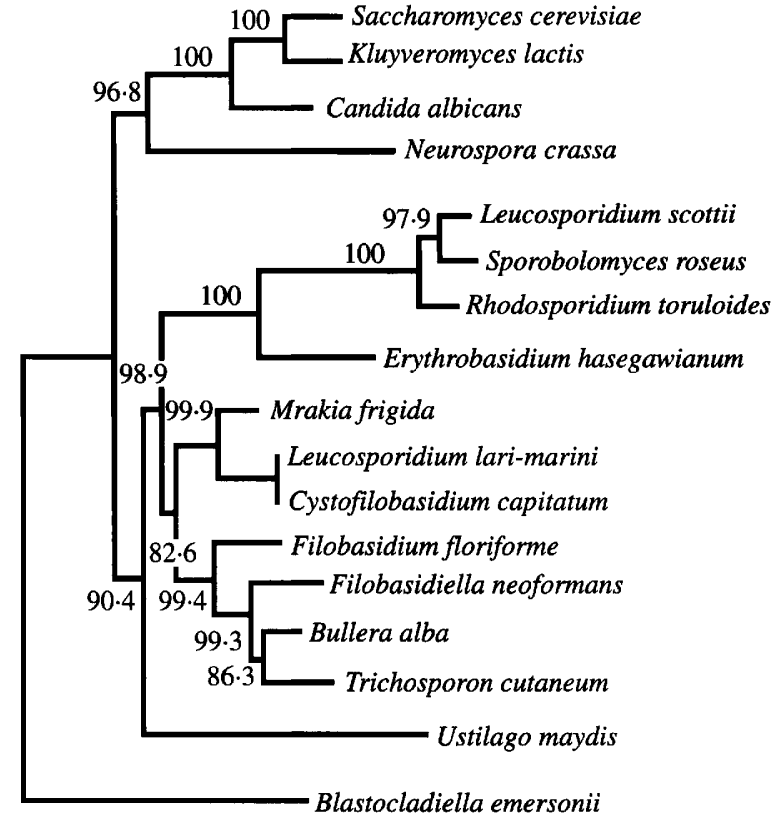

$\overline{0 \cdot 01}$

Fig. 1. Evolutionary tree of 17 species based on 1623 sites among about 1750 bases of $18 \mathrm{~S}$ rDNA. The tree was constructed from the evolutionary distance data according to Kimura (1980) using the neighbour-joining method (Saitou \& Nei, 1987). Each number indicates the percentage of bootstrap samplings, derived from 1000 samples, supporting the internal branches. The distance corresponding to one base change per hundred nucleotide positions is indicated by a bar.

a phylogenetic tree (Fig. 1) was constructed from these sequences using the neighbour-joining method (Saitou \& Nei, 1987). Four ascomycete and twelve basidiomycete genera were well-separated, based on the 1623 sites compared. The phylogenic tree divided the basidiomycetous yeasts into two groups, which correlated well

Table 1. Basidiomycetous yeast species and selected taxonomic characteristics

\begin{tabular}{|c|c|c|c|c|c|}
\hline Species & $\begin{array}{l}\text { Septal pore } \\
\text { structure* }\end{array}$ & $\begin{array}{l}\text { Xylose in } \\
\text { the cells }{ }^{\dagger}\end{array}$ & $\begin{array}{l}\text { Major } \\
\text { ubiquinone } \\
\text { system } \ddagger\end{array}$ & Teliospore§ & $\begin{array}{c}\text { Basidial } \\
\text { form§ }\end{array}$ \\
\hline Leucosporidium scottii & Simple & - & 9,10 & + & Phragmo \\
\hline Leucosporidium lari-marini & Dolipore & + & 8 & + & Holo \\
\hline Rhodosporidium toruloides & Simple & - & 9 & + & Phragmo \\
\hline Erythrobasidium hasegawianum & Simple & - & $10\left(\mathrm{H}_{2}\right)$ & - & Holo \\
\hline Cystofilobasidium capitatum & Dolipore & + & 8 & + & Holo \\
\hline Mrakia frigida & Dolipore & + & 8 & + & Holo \\
\hline Filobasidium floriforme & Dolipore & + & 10 & - & Holo \\
\hline Filobasidiella neoformans & Dolipore & + & 10 & - & Holo \\
\hline
\end{tabular}

* Data from Johnson-Reid \& Moore (1972), Kwon-Chung \& Popkin (1976), Nakagiri \& Tubaki (1983), Moore (1972), Moore \& Kreger-van Rij (1972), Obwerwinkler et al. (1983), Suh \& Sugiyama (1993) and Suh et al. (1993).

† Data from Sugiyama et al. (1985), Suh \& Sugiyama (1993).

† Data from Sugiyama et al. (1985), Suh \& Sugiyama (1993), Yamada \& Kondo (1972a, b, 1973).

$\S$ Data from Fell \& Statzell-Tallman (1992), Hamamoto et al. (1988), Kreger van Rij (1984b) and Saez \& Nguyen (1989). 
with the septal pore type and cellular carbohydrate composition profile (Table 1).

From 5S rRNA comparisons, Walker \& Doolittle $(1982,1983)$ and Blanz \& Unseld (1987) concluded that septal pore structures were of great value as a taxonomic tool in basidiomycetes. This is confirmed by the trees produced from complete $18 \mathrm{~S}$ rDNA sequences, as shown in Fig. 1 and in the paper by Van de Peer et al. (1992).

Hamamoto et al. (1988) discovered the teleomorphic state of Rhodotorula hasegawae, which is characterized by unicellular basidia, the lack of teliospores, and the type of ubiquinone $\left(\mathrm{Q}-10 / \mathrm{H}_{2}\right)$. They proposed the new genus Erythrobasidium for the teleomorph and tentatively placed it in the Filobasidiaceae. However, Suh et al. (1993) suggested from data on hyphal septal pore ultrastructure that Erythrobasidium has an affinity with the teliospore-forming yeasts rather than with the filobasidiaceous taxa. Erythrobasidium hasegawianum (Hamamoto et al., 1991), the type species of this genus, is of the simple septal pore type, which is very similar to that of Rhodosporidium toruloides and related taxa (Johnson-Reid \& Moore, 1972; Kreger-van Rij \& Veenhuis, 1971; Moore, 1972; Suh et al., 1993; cf. Table 1). This association is supported by the molecular phylogeny based on 18S rDNA sequence (Fig. 1), which relates $E$. hasegawianum to the teliospore-forming yeast species $R$. toruloides and $L$. scottii. The bootstrap analysis supported the topologies of this group including $L$. scottii, $R$. toruloides and E. hasegawianum, at the $100 \%$ confidence level.

Cystofilobasidium and Mrakia have been distinguished from Rhodosporidium and Leucosporidium mainly by ultrastructural and chemotaxonomic data and were assigned to the Filobasidiaceae (Oberwinkler et al., 1983; Yamada \& Komagata, 1987). In C. capitatum and $M$. frigida, the septal pores are dolipores similar to other genera of the Filobasidiaceae (Nakagiri \& Tubaki, 1983; Oberwinkler et al., 1983; Suh et al., 1993; cf. Table 1). Cystofilobasidium capitatum and $M$. frigida were well separated from $R$. toruloides and $L$. scottii, and showed a relationship with Filobasidium floriforme, the type genus and type species of the Filobasidiaceae, and Filobasidiella neoformans (Fig. 1).

Buff-coloured Leucosporidium lari-marini showed a very close relationship with the reddish-coloured $C$. capitatum originally assigned to the genus Rhodosporidium. No base differences were found in the 1749 bases compared between C. capitatum and L. lari-marini. The two show a close relationship in many taxonomic characteristics: i.e. both species are characterized by the Q-8 ubiquinone system, xylose in their cellular carbohydrates and dolipore-like septa without typical parenthesomes (Suh \& Sugiyama, 1993; cf. Table 1). The close relationships between $L$. lari-marini, C. capitatum and $M$. frigida were supported at the $99.9 \%$ confidence level in a bootstrap test. Recently, Fell \& StatzellTallman (1992) transferred L. lari-marini to Cystofilobasidium as $C$. lari-marini on the basis of a comparison of 26S rRNA partial sequences, and the use of basidial morphology. Our 18S rDNA data supported this transfer but more information, including DNA base composition and DNA-DNA hybridization, is needed to assign $L$. lari-marini precisely at the species level.

Basidiomycetous anamorphic yeasts were also divided into two phylogenetic groups, which correlated with their teleomorphs. Sporobolomyces roseus, an anamorph of Sporidiobolus in teliospore-forming yeasts, was related to L. scottii. On the other hand, Bullera alba and Trichosporon cutaneum were related to $F$. neoformans and $F$. floriforme. The phylogenetic tree (Fig. 1) correlated well with the cellular carbohydrate composition profiles. Unlike B. alba (von Arx \& Weijman, 1979), S. roseus has no xylose (Crook \& Johnston, 1962).

In conclusion, the molecular phylogeny based on $18 \mathrm{~S}$ rRNA gene sequences divided twelve representatives of the basidiomycetous yeasts into two lineages (the teliospore-forming yeasts, including Erythrobasidium hasegawianum, and the Filobasidiaceae, including Leucosporidium lari-marini) and showed a good correlation with the septal pore type and cellular carbohydrate composition. The value of these properties as taxonomic characters has thus been supported by the molecular data.

\section{References}

von ArX, J. A. \& Weijman, A. C. M. (1979). Conidiation and carbohydrate composition in some Candida and Torulopsis species. Antonie van Leeuwenhoek 45, 547-555.

Berbee, M. L. \& TAYLOR, J. W. (1992a). Convergence in ascospore discharge mechanism among pyrenomycete fungi based on $18 \mathrm{~S}$ ribosomal RNA gene sequence. Molecular Phylogenetics and Evolution 1, 59-71.

BerbeE, M. L. \& TAYLOR, J. W. (1992b). Two Ascomycete classes based on fruiting-body characters and ribosomal DNA sequence. Molecular Biology and Evolution 9, 278-284.

BLANZ, P. A. \& UNSELD, M. (1987). Ribosomal RNA as a taxonomic tool in mycology. In The Expanding Realm of Yeast-like Fungi, pp. 247-258. Edited by G. S. de Hoog, M. Th. Smith \& A. C. M. Weijman. Amsterdam: Elsevier Science Publishers.

Bruns, T. D., White, T. J. \& TAYLoR, J. W. (1991). Fungal molecular systematics. Annual Review of Ecology and Systematics 22, 525-564.

Crook, E. M. \& Johnston, I. R. (1962). The qualitative analysis of the cell walls of selected species of fungi. Biochemical Journal 83, 325-331.

De Wachter, R., Neefs, J.-M., Goris, A. \& Van de Peer, Y. (1992). The gene coding for small ribosomal subunit RNA in the basidiomycete Ustilago maydis contains a group I intron. Nucleic Acids Research 20, 1251-1257.

Fell, J. W. \& Statzell-Tallman, A. (1992). Systematic placement of the basidiomycetous yeast $C y$ stofilobasidium lari-marini comb. nov. as predicted by rRNA nucleotide sequence analysis. Antonie van Leeuwenhoek 62, 209-213.

FELSENSTEIN, J. (1985). Confidence limits on phylogenies: an approach using the bootstrap. Evolution 39, 783-791. 
Förster, H., Coffey, M. D., Elwood, H. \& Sogin, M. L. (1990). Sequence analysis of the small subunit ribosomal RNAs of three zoosporic fungi and implications for fungal evolution. Mycologia 82, 306-312.

Hamamoto, M., Sugiyama, J. \& Komagata, K. (1988). Transfer of Rhodotorula hasegawae to a new basidiomycetous genus Erythrobasidium hasegawae comb. nov. Journal of General and Applied Microbiology 34, 279-287.

Hamamoto, M., Sugiyama, J. \& Komagata, K. (1991). Nomenclature of the basidiomycetous yeast species Erythrobasidium hasegawae. Journal of General and Applied Microbiology 37, 131-132.

Hendriks, L., Goris, A., Neers, J.-M., Van De Peer, Y., Neefs, J., HeNNEBERT, G. \& DE WACHTER, R. (1989). The nucleotide sequence of the small ribosomal subunit RNA of the yeast Candida albicans and the evolutionary position of the fungi among the eukaryotes. Systematic and Applied Microbiology 12, 223-229.

Hendriks, L., Goris, A., VAN De Peer, Y., Neefs, J.-M., Vancanneyt, M., Kersters, K., Hennebert, G. L. \& De WAChter, R. (1991 a). Phylogenetic analysis of five medically important Candida species as deduced on the basis of small ribosomal subunit RNA sequences. Journal of General Microbiology 137, 1223-1230.

Hendriks, L., De Baere, R., Van de Peer, Y., Neefs, J.-M., Goris, A. \& DE WACHTER, R. $(1991 b)$. The evolutionary position of the rhodophyte Porphyra umbilicalis and the basidiomycete Leucosporidium scottii among other eukaryotes as deduced from complete sequences of small ribosomal subunit RNA. Journal of Molecular Evolution 32, 167-177.

Hendriks, L., Goris, A., Van de Peer, Y., Neefs, J.-M., Vancanneyt, M., Kersters, K., Berny, J., HenNeBert, G. L. \& DE WAChter, R. (1992). Phylogenetic relationships among Ascomycetes and Ascomycete-like yeast as deduced from small ribosomal subunit RNA sequences. Systematic and Applied Microbiology 15, 98-104.

HibBetT, D. A. (1992). Ribosomal RNA and fungal systematics. Transactions of the Mycological Society of Japan 33, 533-556.

Higgins, D. G., Bleasby, A. J. \& Fuchs, R. (1992). Clustal v: improved software for multiple sequence alignment. Cabios 8 , 189-191.

JoHnSON-REID, J. A. \& MoORE, R. T. (1972). Some ultrastructural features of Rhodosporidium toruloides Banno. Antonie van Leeuwenhoek 38, 417-435.

KIMURA, M. (1980). A simple method for estimating evolutionary rate of base substitutions through comparative studies of nucleotide sequences. Journal of Molecular Evolution 16, 111-120.

KoHN, L. M. (1992). Developing new characters for fungal systematics: an experimental approach for determining the rank of resolution. Mycologia 84, 139-153.

KREGER-VAN RIJ, N. J. W. (1984a). Systems of classification of the yeasts. In The Yeasts, pp. 2-13. Edited by N. J. W. Kreger-van Rij. Amsterdam: Elsevier Science Publishers.

KREGER-VAN RIJ, N. J. W. (1984b). The Yeasts, a Taxonomic Study, 3rd Edn. Amsterdam: Elsevier Science Publishers.

KreGer-VAN RiJ, N. J. W. \& Veenhuts, M. (1971). A comparative study of the cell wall structure of basidiomycetous and related yeasts. Journal of General Microbiology 68, 87-95.

KURTZMAN, C. P. (1992). rRNA sequence comparisons for assessing phylogenetic relationships among yeasts. International Journal of Systematic Bacteriology 42, 1-6.

Kwon-ChUnG, K. J. \& PoPKIn, T. J. (1976). Ultrastructure of septal complex in Filobasidiella neoformans (Cryptococcus neoformans). Journal of Bacteriology 126, 524-528.

MaleszKa, R. \& Clark-Walker, G. D. (1990). Sequence of the gene for the cytoplasmic ribosomal RNA small subunit from Kluyveromyces lactis. Nucleic Acids Research 18, 1889.

Mankin, A. S., SkRYabin, K. G. \& Rubstov, P. M. (1986). Identification of ten additional nucleotides in the primary structure of yeast 18S rRNA. Gene 44, 143-145.

MOORE, R. T. (1972). Ustomycota, a new division of higher fungi. Antonie van Leeuwenhoek 38, 567-584.
MOORE, R. T. \& KREGER-VAN RIJ, N. J. W. (1972). Ultrastructure of Filobasidium Olive. Canadian Journal of Microbiology 18, 1949-1951. NAKaGiri, A. \& TUBAKI, K. (1983). A taxonomic study of Rhodosporidium capitatum. Canadian Journal of Botany 61, 1898-1905.

Nishida, H. \& SugiYama, J. (1993). Phylogenetic relationships among Taphrina, Saitoella, and other higher fungi. Molecular Biology and Evolution 10, 431-436.

OberWinkler, F., Bandoni, R., Blanz, P. \& Kisimova-Horovitz, L. (1983). Cystofilobasidium: a new genus in the Filobasidiaceae. Systematic and Applied Microbiology 4, 114-122.

SAEZ, H. \& NGUYEN, T. L. (1989). Leucosporidium lari-marini nouvelle espèce de levure isolée chez un oiseau aquatique. Cryptogamie Mycologie 10, 81-85.

SAITOU, N. \& NeI, M. (1987). The neighbour-joining method: a new method for reconstructing phylogenetic trees. Molecular Biology and Evolution 4, 406-425.

Sogin, M. L., Miotto, K. \& Miller, L. (1986). Primary structure of the Neurospora crassa small subunit ribosomal RNA coding region. Nucleic Acids Research 14, 9540.

Sugiyama, J., Fukagawa, M., Chiu, S.-W. \& Komagata, K. (1985). Cellular carbohydrate composition, DNA base composition, ubiquinone systems, and Diazonium Blue B color test in the genera Rhodosporidium, Leucosporidium, Rhodotorula and related basidiomycetous yeasts. Journal of General and Applied Microbiology 31, 519-550.

SuH, S.-O. \& Sugryama, J. (1993). Septal pore ultrastructure of Leucosporidium lari-marini, a basidiomycetous yeast, and its taxonomic implications. Journal of General and Applied Microbiology 39 (in the Press).

SuH, S.-O., Hirata, A., Sugiyama, J. \& Komagata, K. (1993). Septal ultrastructure of basidiomycetous yeasts and their taxonomic implications with observations on the ultrastructure for Erythrobasidium hasegawianum and Sympodiomycopsis paphiopedili. Mycologia 85, 30-37.

VAN DE PeER, Y., Hendriks, L., Goris, A., NeEFs, J.-M., VANCANNEYT, M., Kersters, K., Berny, J.-F., Hennebert, G. L. \& De WaChter, R. (1992). Evolution of basidiomycetous yeasts as deduced from small ribosomal subunit RNA sequences. Systems of Applied Microbiology 15, 250-258.

WaLKeR, W. F. \& Doolittle, W. F. (1982). Redividing the basidiomycetes on the basis of 5S rRNA nucleotide sequences. Nature, London 299, 723-724.

WALKER, W. F. \& DoolitTle, W. F. (1983). 5S rRNA sequences from eight basidiomycetes and fungi imperfecti. Nucleic Acids Research 11, 7625-7630.

Yamada, Y. \& Komagata, K. (1987). Mrakia gen. nov., a heterobasidiomycetous yeast genus for the Q8-equipped, self-sporulating organisms which produce a unicellular metabasidium, formerly classified in the genus Leucosporidium. Journal of General and Applied Microbiology 33, 455-457.

YAMADA, Y. \& Kondo, K. (1972a). Taxonomic significance of coenzyme Q system in yeasts and yeast-like fungi (1). In Yeasts, Models in Science and Technics, pp. 363-373. Edited by A. KockováKratochvílová \& E. Minárik. Bratislava: Publishing House of the Slovak Academy of Sciences.

YAMADA, Y. \& Kondo, K. (1972b). Taxonomic significance of the coenzyme $\mathrm{Q}$ system in yeasts and yeast-like fungi. In Yeasts and Yeast-like Microorganisms in Medical Science, pp. 63-69. Edited by K. Iwata. Tokyo: University of Tokyo Press.

YamadA, Y. \& Kondo, K. (1973). Coenzyme Q system in the classification of the yeast genera Rhodotorula and Cryptococcus, and the yeast-like genera Sporobolomyces and Rhodosporidium. Journal of General and Applied Microbiology 19, 59-77.

Yamada, Y., Nakagawa, Y. \& BanNo, I. (1989). The phylogenetic relationships of the Q9-equipped species of the heterobasidiomycetous yeast genera Rhodosporidium and Leucosporidium based on $18 \mathrm{~S}$ and $26 \mathrm{~S}$ ribosomal ribonucleic acids: The proposal of a new genus Kondoa. Journal of General and Applied Microbiology 35, 377-385. 